\title{
THE HR DIAGRAM
}

Edited by A. G. DAVIS PHILIP and D. S. HAYES
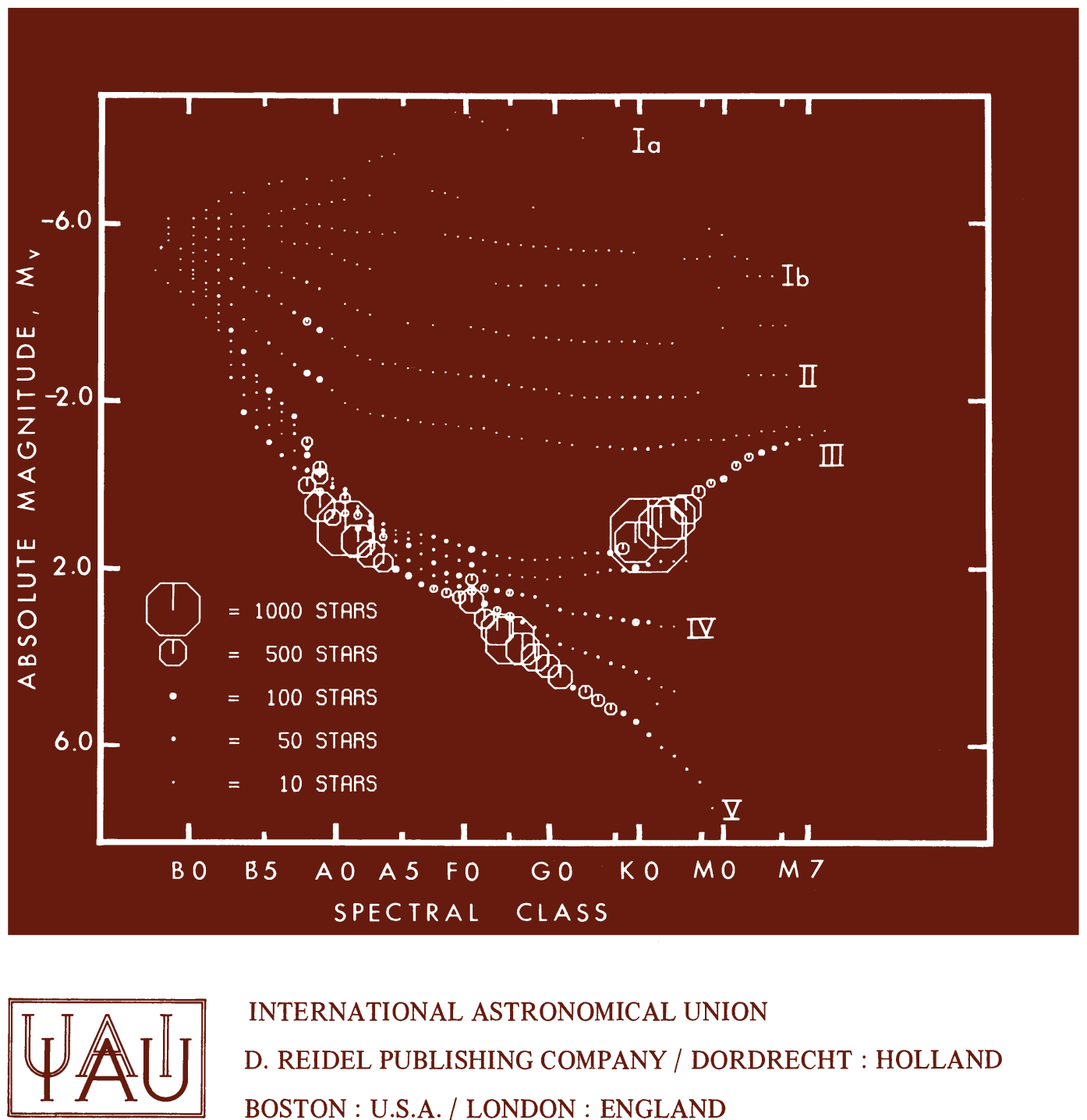

INTERNATIONAL ASTRONOMICAL UNION

D. REIDEL PUBLISHING COMPANY / DORDRECHT : HOLLAND BOSTON : U.S.A. / LONDON : ENGLAND 
SYMPOSIUM No. 72

A B UNDANCE EFFECT S

I N C L A S I F I C A T I O N

SYMPOSIUM No. 73

STRUCTURE AND

EVOLUTION OF

CLOSE BINARY S Y T EMS

SYMPOSIUM No. 74

RADIOASTRONOMY

AND COSMOLOGY

SYMPOSIUM No. 75

STAR FORMATION

SYMPOSIUM No. 76

PLANETAR Y NEBULAE

SYMPOSIUM No. 77

STRUCTURE AND

PROPERTIES OF NEARBY

G A L A X I E S

SYMPOSIUM No. 78

NUTATION AND THE

EARTH'S ROTATION

SYMPOSIUM No. 79

THE LARGE SCALE

STRUCTURE OF

THE UNIVERSE

D. REIDEL PUBLISHING COMPANY

DORDRECHT : HOLLAND / BOSTON : U.S.A.

LONDON : ENGLAND 
THE HR DIAGRAM 


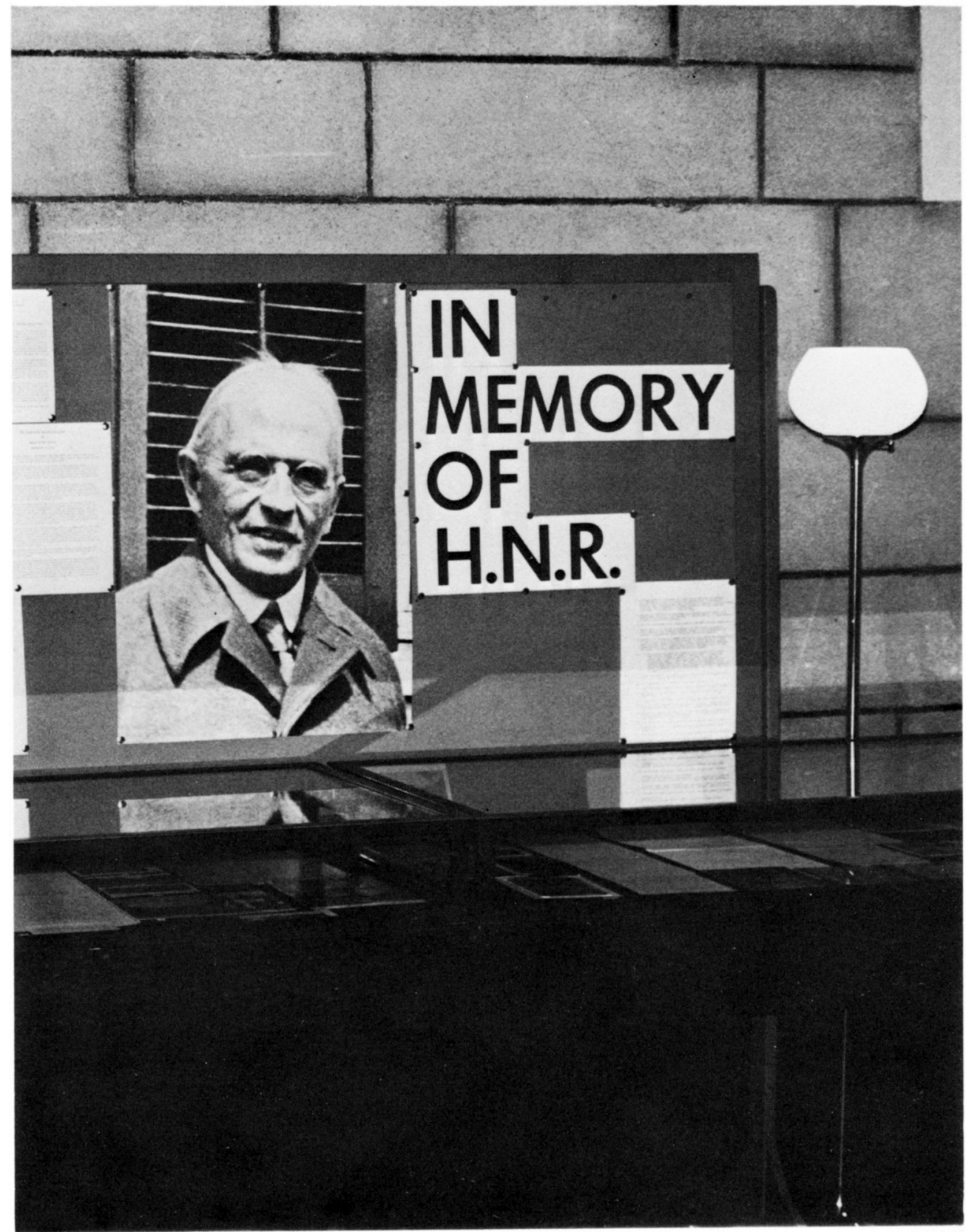

HENRY NORRIS RUSSELL 
INTERNATIONAL ASTRONOMICAL UNION

UNION ASTRONOMIQUE INTERNATIONALE

SYMPOSIUM No. 80

HELD AT THE NATIONAL ACADEMY OF SCIENCES, WASHINGTON D.C.

2-5 NOVEMBER, 1977

\section{THE HR DIAGRAM}

The 100th Anniversary of Henry Norris Russell

EDITED BY

A. G. DAVIS PHILIP

Dudley Observatory and Union College

AND

D. S. HAYES

Arizona State University

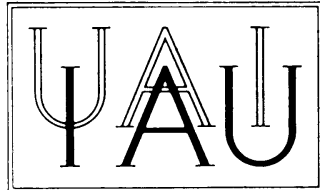

D. REIDEL PUBLISHING COMPANY

DORDRECHT : HOLLAND / BOSTON : U.S.A./ LONDON : ENGLAND

1978 


\title{
Library of Congress Cataloging in Publication Data
}

Main entry under title:

The HR Diagram.

(Symposium - International Astronomical Union ; no. 80)

Includes bibliographies and indexes.

1. HR diagrams - Congresses. 2. Stars - Congresses. 3. Russell, Henry Norris, 1877-1957. I. Russell, Henry Norris, 1877-1957. II. Philip, A. G. Davis. III. Hayes, Donald S. IV. Series: International Astronomical Union. Symposium ; no. 80 .

QB815.H18 $\quad 523.8 \quad 78-19125$

ISBN 90-277-0905-X

ISBN 90-277-0906-8 pbk.

\author{
Published on behalf of \\ the International Astronomical Union \\ by \\ D. Reidel Publishing Company, P. O. Box 17, Dordrecht, Holland
}

All Rights Reserved

Copyright $\bigcirc 1978$ by the International Astronomical Union

Sold and distributed in the U.S.A., Canada, and Mexico

by D. Reidel Publishing Company, Inc.

Lincoln Building, 160 Old Derby Street, Hingham,

Mass. 02043, U.S.A.

No part of the material protected by this copyright notice may be reproduced or utilized in any form or by any means, electronic or mechanical, including photocopying, recording or by any informational storage and retrieval system, without written permission from the publisher

Printed in The Netherlands 

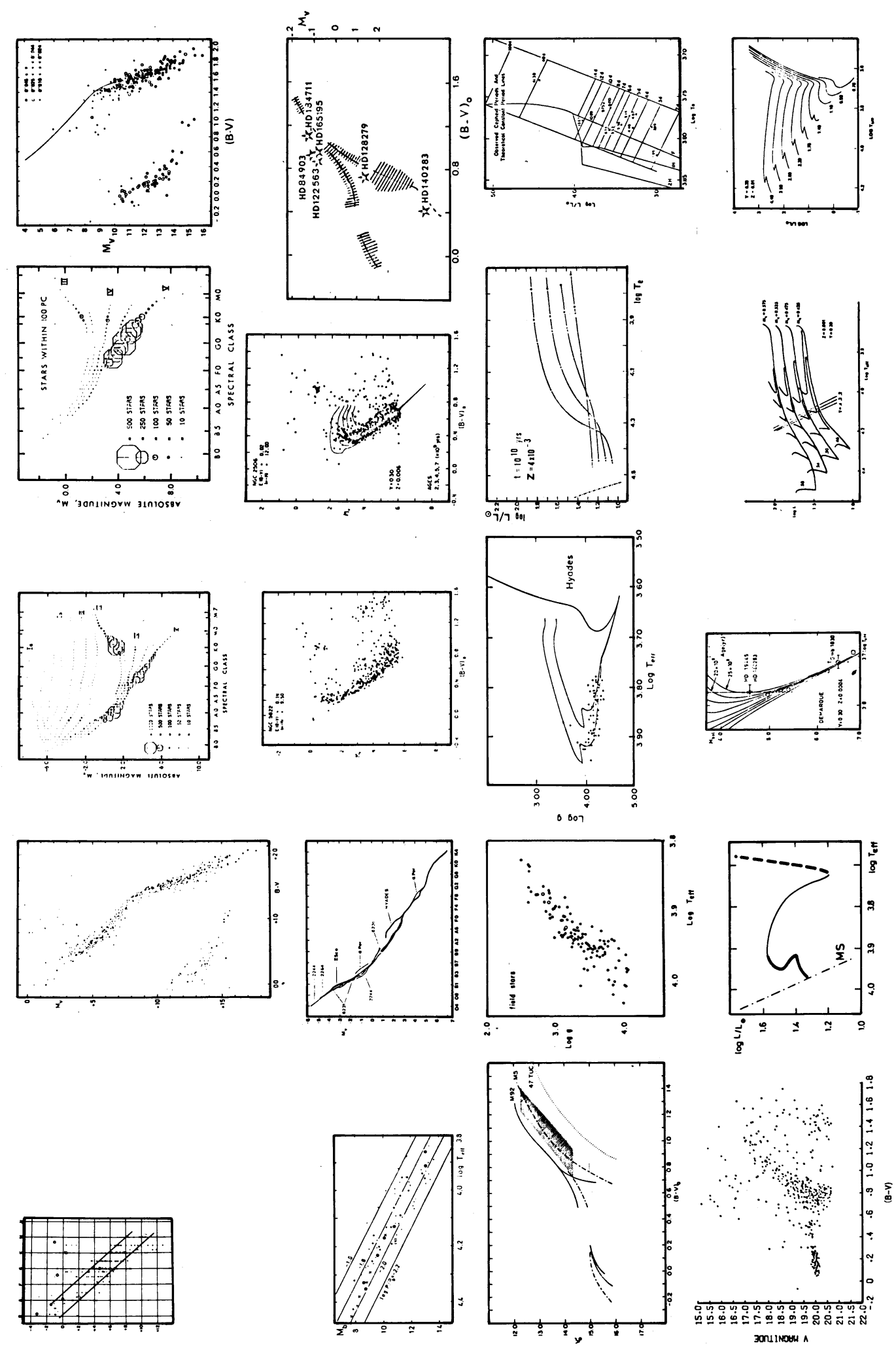
Preface

W.W. MORGAN / Some Uses of Spectral Classification in HR Diagrams

NOLAN R. WALBORN / Some Progress and Problems in the Upper Left of the HR Diagram

PHILIP C. KEENAN / A More Accurate HR Diagram for the Cooler Stars

PATRICIA C. BOESHAAR / Spectroscopic Observations of Late-Type Halo M Dwarfs

I. APPENZELLER and H. ZEKL / A Computer Method for Spectra1 Classification

M. PARTHASARATHY / Red and Blue Stars in the Direction of the Large Magellanic Cloud

TH. SCHMIDT-KALER / Quantitative Two-Dimensional Classifications of Low Dispersion Objective Prism Spectra

V.M. BLANCO, A.A. HOAG, and M.F. McCARTHY / Carbon and LateType M Stars as Population Indicators

ARTHUR R. UPGREN / Main Sequences Defined by Hyades and Field Stars

ANDRÉ HECK / Absolute Magnitudes by Statistical Parallaxes

S.V.M. CLUBE and J.A. DAWE / RR Lyrae Variable Stars and the Distance Scale

ROBERT E. STENCEL / Extensions of the Wilson-Bappu Effect Among Very Luminous Stars

WILLEM J. LUYTEN / Statistical HR Diagrams for One Hundred and Fifteen Thousand Proper-Motion Stars

D.S. HAYES / The Absolute Calibration of the HR Diagram: Fundamental Effective Temperatures and Bolometric Corrections

II. HR DIAGRAMS, THE SOLAR NEIGHBORHOOD

W. GLIESE / Hertzsprung-Russe11 Diagrams and Color-Luminosity 
Diagrams for the Stars Nearer than Twenty-Two Parsecs 79

DON C. BARRY / The Position of the Sun in the HR Diagram

NANCY HOUK and ROBERT FESEN / HR Diagrams Derived from the Michigan Spectral Catalogue

III. HR DIAGRAMS, SUBLUMINOUS STARS

JESSE L. GREENSTEIN / The HR Diagram

HARRY L. SHIPMAN / The Distribution of Masses and Radii of White Dwarf Stars

VOLKER WEIDEMANN / The HR Diagram of White Dwarfs

PAUL R. WESSELIUS / U1traviolet Colors of Subdwarf O Stars

C.C. DAHN and R.S. HARRINGTON / Subluminous Stars in the HR Diagram

S. TAPIA / Empirical Evidence for Crystallization Sequences of DA Type White Dwarfs

\section{HR DIAGRAMS, CLUSTERS}

A. GUTIÉRREZ-MORENO and H. MORENO / Spectrophotometry in Stellar Associations

WILLIAM HERBST and ROBERT J. HAVLEN / A Photometric Study of Ara OB 1

D.L. CRAWFORD / Four-Color and HB Diagrams for Open Clusters A Survey

R.F. GARRISON / The Main Sequence of NGC 6231 and the Calibration of Absolute Magnitudes

PHILLIP J. FLOWER / The Hyades Cluster - Too Distant?

HELMUT A. ABT and HUGO LEVATO / The Occurrence of Peculiar Stars in Open Clusters

CATHERINE A. PILACHOWSKI and WALTER K. BONSACK / The Clump Giants: A Spectroscopic Survey of $G$ and $\mathrm{K}$ Giants in Open Clusters

RICHARD C. HENRY and JAMES E. HESSER / K-Line Photometry: Coma and NGC 6475

ALAN HIRSHFELD, ROBERT D. McClURE, and BRUCE A. TWAROG / Measurements of Abundances and Ages of Old Disk Clusters

ROBERT P. KRAFT / Evidence for Non-Homogeneity in the Metal Abundances of Stars in Globular Clusters 
M. SPITE and F. SPITE / A Comparison Between the Relative Heavy Metal Abundance of the Extreme Halo Field Stars and Giant Stars of Globular Clusters

GEORGE WALLERSTEIN and CATHERINE PILACHOWSKI / Observations of $\mathrm{CO}$ and $\mathrm{OI}$ in Stars in Globular Clusters

R. CANTERNA and R.A. SCHOMMER / The Chemical Abundances of the Halo Clusters of the Galaxy

DENNIS BUTLER, ROGER A. BELL, R.J. DICKENS, and ELIZABETH EPPS / A Combined Photometric/Spectrosconic Study of RR Lyrae Stars in the Globular Cluster Omega Centauri

JOHN NORRIS / The Role of Mixing and Primordial Abundance Variations in 47 Tucanae and $\omega$ Centauri

T. LLOYD EVANS / The Anomalous Giant Branch of $\omega$ Centauri 205

V. HR DIAGRAMS, HORIZONTAL BRANCH

A.G. DAVIS PHILIP / Horizontal-Branch Stars in the Log $\mathrm{T}_{\text {eff }}$, Log G Diagram

VITTORIO CASTELLANI / The Expected Morphology of Zero Age Horizontal Branches

F. FUSI-PECCI and A. RENZINI / Evolution of Globular Cluster Stars with Mass Loss and Core Rotation

J.W. PEL and J. LUB / Physical Properties of Cepheids and RR Lyrae Stars

ARTHUR N. COX and STEPHEN W. HODSON / Pulsation Modal Behavior of Classical Cepheids in the HR Diagram

L.A. BALONA / The Radii of RR Lyrae Stars

\section{GALAXIES AND MISCELLANEOUS SUBJECTS}

BEATRICE M. TINSLEY / HR Diagrams of Galaxies: Ages and Stages of Evolution

DAVID CRAMPTON / Luminosities of LMC OB Stars

ROBERTA M. HUMPHREYS / The HR Diagram for Luminous Stars in Nearby Galaxies

ROBERT A. SCHOMMER, EDWARD W. OLSZEWSKI, and WILLIAM E. KUNKEL / A Preliminary Color-Magnitude Diagram for the Ursa Minor Dwarf Galaxy

SIDNEY VAN DEN BERGH / The Hertzsprung-Russel1 Diagram of Meta1Poor Disk Stars 
M. GOLAY / The Use of Praesepe for the Definition of the Lower Part of the Zero-Age Main Sequence

DAVID S. EVANS / A New Kind of HR Diagram?

B. HAUCK / Detection of Am and Ap Stars by Photometric Means

EUGENIO E. MENDOZA V / The HR Diagram of Abnormal A-Type Stars

V. STRAIŽYS / From Multicolor Photometric Indices to the HR Diagram

\section{THEORETICAL PAPERS AND SUMMARY}

HELMUTH KÄHLER / The Vogt-Russe11 Theorem, and New Results on an 0ld Problem

G. CAYREL DE STROBEL and M.N. PERRIN / Comparison Between Observational and Theoretical ( $\log \mathrm{T}_{\text {eff }}, \mathrm{M}_{\mathrm{bol}}$ ) Diagrams

M.N. PERRIN and G. CAYREL DE STROBEL / Is it Possible to Derive the Position of a Star in the HR Diagram from Multicolor Photometry?

PETER G. GROSS / On Magnetic Mixing and Rotation in Stellar Evolution

ALLEN V. SWEIGART / Survey of Some Recent Stellar-Evolution Calculations

R.B. CIARDULlO and P. DEMARQUE / The Evolution of the Integrated Colors of Globular Clusters and Elliptical Galaxies

SUSAN A. LAMB / Evolution of Massive Stars Through Late Evolutionary Phases

C. CHIOSI / The Structure and Evolution of Massive Stars

PETER S. CONTI / Evolution of Massive Stars: When Does an of Star Become a WR Star?

DAVID S.P. DEARBORN and VIRGINIA TRIMBLE / Nucleosynthesis in Massive Population II Stars

R.A. BELL and B. GUSTAFSSON / The Colors of G and K Giant Stars 379

R. FOY / Microturbulence as a Third Dimension in the G-K Giant Region of the HR Diagram

KEIICHI KODAIRA / Sphericity Effects of Extended Atmospheres of Late-Type Giants in the HR Diagram

LOUIS C. GREEN / Summary

Continuation of Discussion 
POSTER SESSION

THOMAS B. AKE / A Revised Classification System in the Red for S Stars

H.J. AUGENSEN and W. BUSCOMBE / Southern High-Velocity Stars

WILLIAM P. BIDELMAN / On G.P. Kuiper's Work on the Stars of Large Proper Motion

I. FURENLID and W.L. SANDERS / A B-Star High Luminosity Indicator

JOHANNES HARDORP / The Main Sequence at G2 V

WILLIAM HERBST, RENE RACINE, and JOHN W. WARNER / Optical and Infrared Properties of the Newly Formed Stars in CMa Rl

KEIICHI ISHIDA and TAKAO MIKAMI / Luminosity Calibration of Late-Type Stars by Statistical Parallax using AGK3 Proper Motions

H.E. JØRGENSEN / Fundamental Parameters and the Helium Content of Eclipsing Spectroscopic Binaries

JAMES LIEBERT / Extending the White Dwarf Sequence: Plans and Prospects

BERNARD J. McNAMARA and W.L. SANDERS / Peculiarities in Some Cluster Color-Magnitude Diagrams

LAWRENCE J. RELYEA and A.G. DAVIS PHILIP / The Strömgren FourColor System and the Log $\mathrm{T}_{\text {eff }}$, Log G Diagram

NATHANIEL M. WHITE / Angular Diameters of Cool Stars Measured by the Method of Lunar Occultations

ROBERT F. WING and NATHANIEL M. WHITE / Two-Dimensional Spectral Classification of M Stars by Narrow-Band Photometry

Index 